\title{
Evolution of Pediatric Cardiology over the Last 50 Years (Trends in Transcatheter Interventions for Pediatric Heart Disease - Part I)
}

\section{P Syamasundar Rao, MD*}

Professor of Pediatrics and Medicine, Emeritus Chief of Pediatric Cardiology, Children's Memorial Hermann Hospital, University of Texas-Houston McGovern Medical School, USA

*Corresponding author: P Syamasundar Rao, MD, Professor and Emeritus Chief of Pediatric Cardiology, Children's Memorial Hermann Hospital, University of Texas-Houston McGovern Medical School, 6410 Fannin, UTPB Suite \# 425, Houston, Texas, 77030, USA, Tel: 713-500-5738, Fax: 713-500-5171

\section{Introduction}

The author has just written a book on the evolution of the specialty of Pediatric Cardiology over the last 50 years [1]. The intent of this review is to present a summary of this book. Because of large amount of this material, the review is separated into four parts. In this first part, transcatheter interventions (balloon angioplasty/valvuloplasty procedures) will be appraised.

\section{Historical Aspects Trans-Catheter Interven- tions}

Based a thorough review of the literature it appears that Rubio-Alvarez, et al. [2,3] were the very first to do and report transcatheter intervention to treat congenital cardiac defects (CHDs) in 1953; they performed pulmonary valvotomy using a modified ureteral catheter [2,3]. Nearly a decade later Dotter [4], Rashkind [5], Porstmann [6], and their colleagues described progressive dilatation of peripheral arterial stenotic lesions, balloon atrial septostomy, and percutaneous closure of patent ductus arteriosus (PDA), respectively. This and other reviews [7-9] were intended to present historical developments of catheter-based procedures in the treatment of heart disease in children. Historical aspects of 1) Balloon angioplasty/valvuloplasty of valvar pulmonary stenosis, valvar aortic stenosis, fixed subaortic stenosis, native aortic coarctation, postsurgical aortic recoarctation, branch pulmonary artery stenosis, mitral stenosis, cyanotic CHDs with pulmonary oligemia, stenotic bioprosthetic valves, congenital tricuspid and mitral stenosis, truncal valve stenosis, subvalvar pulmonary stenosis, supravalvar pulmonary stenosis (congenital membranous or postoperative), stenosis of the aorta (Leriche syndrome, atherosclerotic and Takayasu's arteritis), baffle obstruction following Mustard or Senning procedure (both systemic and pulmonary venous obstructions), superior and inferior vena caval obstructions, pulmonary vein stenosis, pulmonary veno-occlusive disease, vertical vein stenosis in total anomalous pulmonary venous connection, pulmonary venous obstruction following repair of total anomalous pulmonary venous connection, specially designed pulmonary artery bands, cor triatriatum, cor triatriatum dexter, and coronary artery stenotic lesions that develop after Kawasaki disease; 2) Stents to enlarge stenotic lesions of branch pulmonary arteries, systemic veins, systemic and pulmonary venous pathways after Mustard procedure, aorta, right ventricular outflow conduits, pulmonary veins and native right ventricular outflow tract or to keep the ductus arteriosus open in patients with pulmonary atresia and hypoplastic left heart syndrome and maintaining patency of stenosed aorto-pulmonary collateral vessels, surgically created but obstructed shunts or acutely thrombosed shunts as well as covered stents; 3 ) Trans-catheter occlusion of cardiac defects comprising of atrial septal defect,

Citation: Rao PS (2021) Evolution of Pediatric Cardiology over the Last 50 Years (Trends in Transcatheter Interventions for Pediatric Heart Disease - Part I). Int J Clin Cardiol 8:220. doi.org/10.23937/23782951/1410220

Accepted: March 06, 2021: Published: March 08, 2021

Copyright: (c) 2021 Rao PS, et al. This is an open-access article distributed under the terms of the Creative Commons Attribution License, which permits unrestricted use, distribution, and reproduction in any medium, provided the original author and source are credited. 
Table 1: History of transcatheter interventions for pediatric heart disease*.

\begin{tabular}{|c|c|c|c|}
\hline Author & Year & Procedure & Lesions addressed \\
\hline Rubio-Alvarez, et al. & 1953 & Pulmonary valvotomy & Pulmonary and tricuspid valve stenosis \\
\hline Dotter and Judkins & 1964 & Dilatation of stenotic lesions & Stenotic lesions of the peripheral arteries \\
\hline Dotter and Judkins & 1964 & Concept of stents & To keep open stenotic vascular lesions \\
\hline Rashkind and Miller & 1966 & Balloon atrial septostomy & Enlargement of atrial septal defect \\
\hline Porstmann, et al. & 1967 & Transcatheter occlusion & Closure of patent ductus arteriosus \\
\hline Dotter & 1969 & Design of stents & To keep open stenotic vascular lesions \\
\hline Grüntzig, et al. & $\begin{array}{l}\text { Mid to late } \\
1970 \text { s }\end{array}$ & Balloon angioplasty & $\begin{array}{l}\text { Enlarge stenotic lesions of the peripheral (iliac, } \\
\text { femoral, popliteal), renal, and coronary arteries }\end{array}$ \\
\hline King, et al. & 1974 & Device occlusion & Atrial septal defects \\
\hline Rashkind, et al. & 1975 & Device occlusion & Atrial septal defects \\
\hline Rashkind, et al. & 1975 & Device occlusion & Ventricular septal defects \\
\hline Park, et al. & 1975 & Blade atrial septostomy & Enlargement of atrial septal defect \\
\hline Mills and King & 1976 & Device occlusion & $\begin{array}{l}\text { Closure of atrial septal defect/patent foramen ovale to } \\
\text { prevent paradoxical embolism }\end{array}$ \\
\hline Sos, et al. & 1979 & Balloon angioplasty & Coarctation of the aorta-postmortem \\
\hline Semb, et al. & 1979 & $\begin{array}{l}\text { Rapid withdrawal of an inflated } \\
\text { Berman angiographic catheter }\end{array}$ & Pulmonary valve stenosis \\
\hline Rashkind, et al. & 1979 & Device occlusion & Closure of patent ductus arteriosus \\
\hline Martin, et al. & 1980 & Balloon angioplasty & Stenotic pulmonary arteries \\
\hline Dotter & 1981 & $\begin{array}{l}\text { Introduction of concept of } \\
\text { transcatheter valve replacement }\end{array}$ & Transcatheter valve replacement \\
\hline Kan, et al. & 1982 & Balloon pulmonary valvuloplasy & Pulmonary valve stenosis \\
\hline Singer, et al. & 1982 & Balloon angioplasty & Post-surgical aortic re-coarctation \\
\hline Driscoll, et al. & 1982 & Balloon angioplasty & Pulmonary vein stenosis \\
\hline Lababidi & 1983 & Balloon aortic valvuloplasy & Aortic valve stenosis \\
\hline Sperling, et al. & 1983 & Balloon angioplasty & Coarctation of the aorta-native \\
\hline Inoue, et al. & 1984 & Balloon aortic valvuloplasy & Mitral stenosis \\
\hline Tynan, et al. & 1984 & Balloon pulmonary valvuloplasy & Critical pulmonary stenosis in the neonate \\
\hline Palmaz, et al. & 1986 & $\begin{array}{l}\text { Balloon expandable intraluminal } \\
\text { stents }\end{array}$ & To keep open stenotic vascular lesions \\
\hline $\begin{array}{l}\text { Lababidi and } \\
\text { Weinhaus }\end{array}$ & 1986 & Balloon aortic valvuloplasy & Critical aortic stenosis in the neonate \\
\hline Suarez de Lezo, et al. & 1986 & Balloon angioplasty & Discrete subaortic stenosis \\
\hline Feit, et al. & 1986 & Balloon valvuloplasy & $\begin{array}{l}\text { Porcine bioprosthetic valves in the tricuspid valve } \\
\text { position }\end{array}$ \\
\hline Rao, et al. & $1987 / 1988$ & Balloon pulmonary valvuloplasy & Pulmonary stenosis in complex cyanotic heart defects \\
\hline Shrivatsava, et al. & & Balloon dilatation of atrial septum & Enlargement of atrial septal defect \\
\hline $\begin{array}{l}\text { Lloyd, et al. and } \\
\text { Waldman, et al. }\end{array}$ & 1987 & Balloon valvuloplasy & $\begin{array}{l}\text { Porcine bioprosthetic valves in the pulmonary valve } \\
\text { position }\end{array}$ \\
\hline Calvo, et al. & 1987 & Balloon valvuloplasy & $\begin{array}{l}\text { Porcine bioprosthetic valves in the mitral valve } \\
\text { position }\end{array}$ \\
\hline McKay, et al. & 1988 & Balloon valvuloplasy & $\begin{array}{l}\text { Porcine bioprosthetic valves in the aortic valve } \\
\text { position }\end{array}$ \\
\hline O'Laughlin, et al. & 1991 & Pediatric application of stents & Stents in congenital heart disease \\
\hline Qureshi, et al. & 1991 & $\begin{array}{l}\text { Perforation of an atretic } \\
\text { pulmonary valve using laser wire }\end{array}$ & To open an atretic pulmonary valve \\
\hline Cambier, et al. & 1992 & Gianturco coils & Closure of patent ductus arteriosus \\
\hline Gibbs, et al. & 1992 & $\begin{array}{l}\text { Stenting of the arterial duct for } \\
\text { palliation of pulmonary atresia } \\
\text { patients }\end{array}$ & To keep patent ductus arteriosus open \\
\hline
\end{tabular}




\begin{tabular}{|c|c|c|c|}
\hline Redington, et al. & 1992 & $\begin{array}{l}\text { Perforation of an atretic } \\
\text { pulmonary valve using radio- } \\
\text { frequency wire }\end{array}$ & To open an atretic pulmonary valve \\
\hline Pavcnik, et al. & 1992 & $\begin{array}{l}\text { Experimental evaluation of } \\
\text { a prosthetic aortic valve for } \\
\text { transcatheter placement }\end{array}$ & Transcatheter valve replacement \\
\hline Ruiz, et al. & 1993 & $\begin{array}{l}\text { Stenting of ductus arteriosus in } \\
\text { infants with the hypoplastic left } \\
\text { heart syndrome }\end{array}$ & To keep patent ductus arteriosus open \\
\hline Piechaud, et al. & 1993 & $\begin{array}{l}\text { Perforation of an atretic } \\
\text { pulmonary valve using blunt } \\
\text { guide wire }\end{array}$ & To open an atretic pulmonary valve \\
\hline $\begin{array}{l}\text { Sharafuddin, et al. and } \\
\text { Masura et al. }\end{array}$ & $1996 / 1998$ & Amplatzer duct occluder & Closure of patent ductus arteriosus \\
\hline $\begin{array}{l}\text { Sharafuddin, et al. and } \\
\text { Masura, et al. }\end{array}$ & 1997 & $\begin{array}{l}\text { Device occlusion with Amplatzer } \\
\text { septal occluder }\end{array}$ & Atrial septal defects \\
\hline Rao & 1998 & $\begin{array}{l}\text { Conceptualization of atrial septal } \\
\text { stents }\end{array}$ & Enlargement of atrial septal defects \\
\hline Atz, et al. & 1999 & $\begin{array}{l}\text { Implantation of atrial septal } \\
\text { stents }\end{array}$ & Enlargement of atrial septal defects \\
\hline $\begin{array}{l}\text { Tofeig, et al. and } \\
\text { Thanopoulos, et al. }\end{array}$ & 1999 & $\begin{array}{l}\text { Device occlusion with Amplatzer } \\
\text { muscular VSD device }\end{array}$ & Muscular ventricular septal defects \\
\hline Gunn, et al. & 1999 & Covered stent & $\begin{array}{l}\text { To treat co-existent coarctation and aneurysm of the } \\
\text { aorta }\end{array}$ \\
\hline Latson, et al. & 2000 & $\begin{array}{l}\text { Device occlusion with HELEX } \\
\text { septal occluder }\end{array}$ & Closure of atrial septal defects \\
\hline Bonhoeffer, et al. & 2000 & $\begin{array}{l}\text { Percutaneous replacement of the } \\
\text { pulmonary valve }\end{array}$ & Percutaneous replacement of the pulmonary valve \\
\hline Justino, et al. & 2001 & $\begin{array}{l}\text { Radiofrequency perforation of } \\
\text { the atrial septum }\end{array}$ & Creation of atrial septal defects \\
\hline Hijazi, et al. & 2002 & $\begin{array}{l}\text { Amplatzer membranous VSD } \\
\text { occluder }\end{array}$ & Closure of ventricular septal defects \\
\hline Laudito, et al. & 2006 & $\begin{array}{l}\text { Right ventricular outflow tract } \\
\text { stent in a premature infants with } \\
\text { tetralogy of Fallot }\end{array}$ & To keep the right ventricular outflow tract open \\
\hline McElhinney, et al. & 2010 & US clinical trial of Melody valve & Percutaneous replacement of the pulmonary valve \\
\hline Leon, et al. & 2010 & $\begin{array}{l}\text { Percutaneous replacement of the } \\
\text { aortic valve }\end{array}$ & Percutaneous replacement of the aortic valve \\
\hline Kenny, et al. & 2011 & $\begin{array}{l}\text { international multicenter clinical } \\
\text { trial of Edwards SAPIEN valve }\end{array}$ & Percutaneous replacement of the pulmonary valve \\
\hline Nyboe, et al. & 2013 & $\begin{array}{l}\text { GORE }^{\circledR} \text { CARDIOFORM ASD } \\
\text { Occluder }\end{array}$ & Atrial septal defects \\
\hline Webb, et al. & 2019 & $\begin{array}{l}\text { Percutaneous transcatheter } \\
\text { mitral valve replacement }\end{array}$ & Percutaneous replacement of the mitral valve \\
\hline
\end{tabular}

"For a more detailed discussion, the reader is referred to Chapter 9 on "The historical aspects of trans-catheter intervention of reference [1].

patent foramen ovale (PFO), PDA, ventricular septal defect (VSD), and aorto-pulmonary window; and 4) Catheter-based atrial septostomy such as Rashkind balloon atrial septostomy, Park's blade atrial septostomy, balloon angioplasty of the atrial septum, trans-septal puncture and atrial septal stents were reviewed. The historical aspects were presented in a tabular form (Table 1 ).

\section{Pulmonary Stenosis}

At first, the pathologic features of pulmonary stenosis were reviewed. This is followed by presentation of historical aspects [7-9], indications [10] and the proce- dure of balloon pulmonary valvuloplasty (BPV) (Figure 1) $[11-13]$.

The notion of using balloons larger than the annulus of the pulmonary valve to dilate the pulmonary valve with balloons 1.2 to 1.4 times the pulmonary valve annulus was conceived on the basis of immediate [14] and both immediate and follow-up [15] results. Then, immediate $[16,17]$, intermediate-term $[18,19]$, and long-term [20] follow-up results (Figure 2) were presented which point out excellent results with minimal residual gradients across the pulmonary valve and event-free rates 


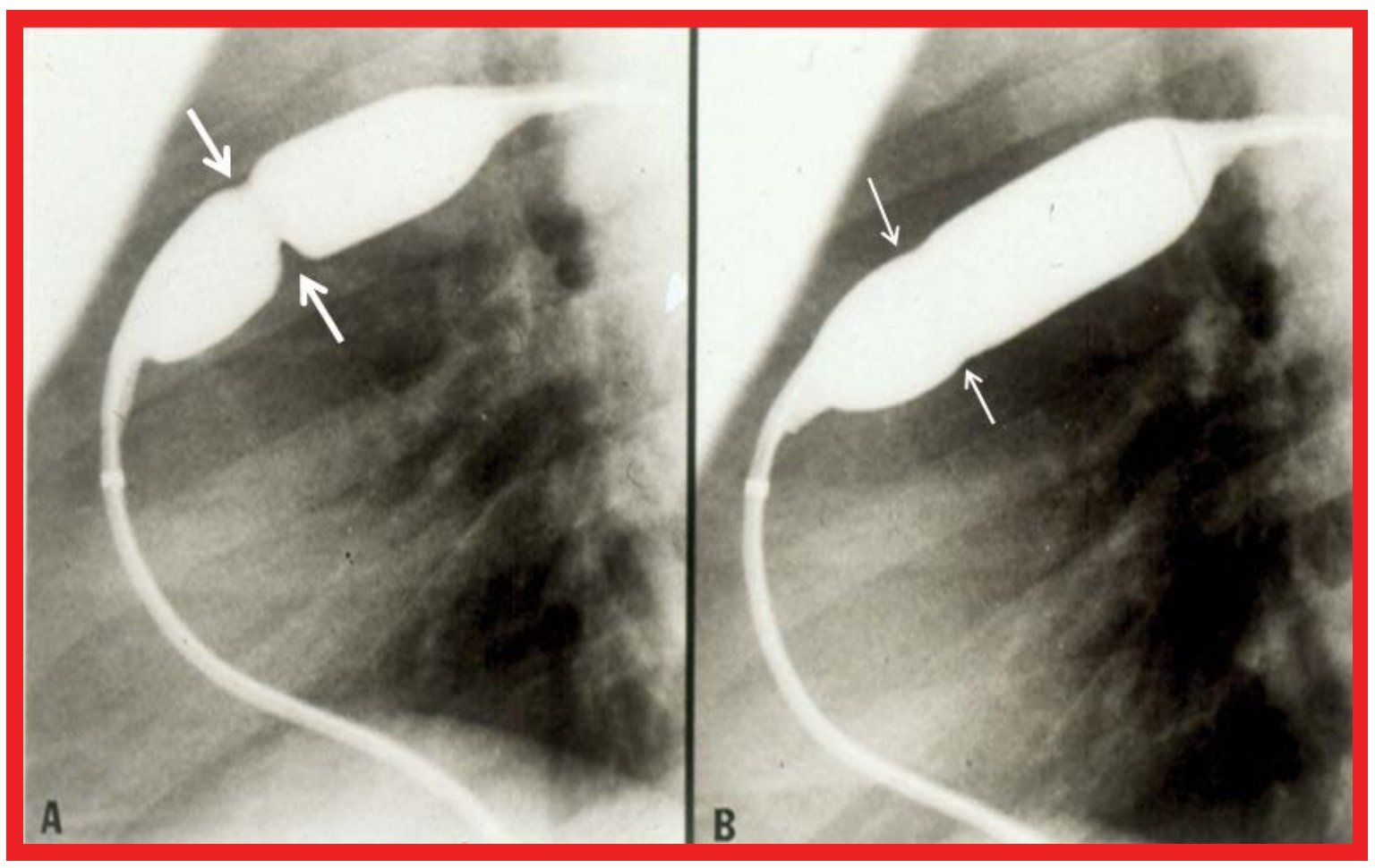

Figure 1: Balloon dilatation catheter placed across the pulmonary valve showing A) "Waisting" of the balloon in the early phases of inflation (thick arrows); B) Which is almost completely abolished with further balloon inflation (thin arrows) [23].

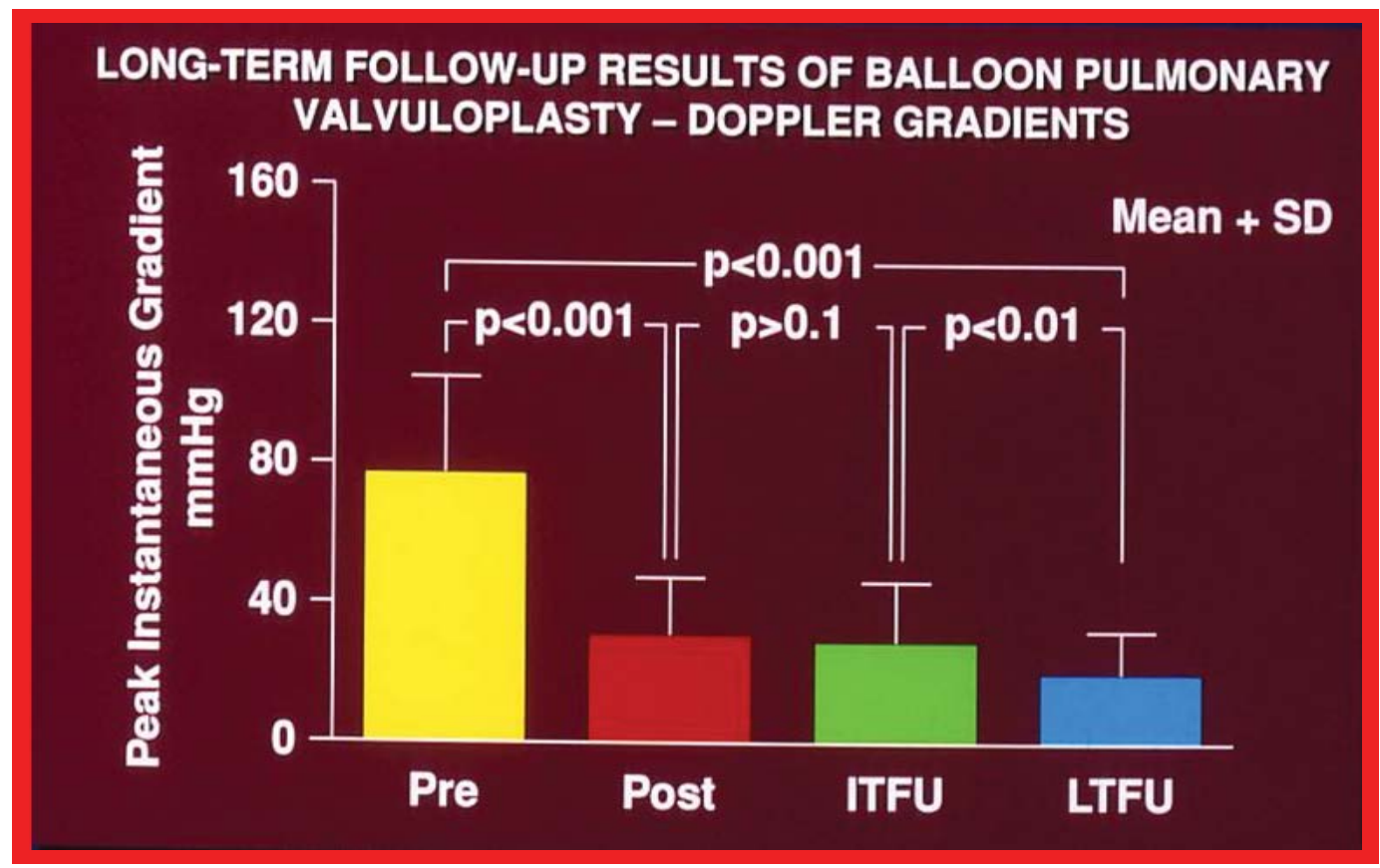

Figure 2: Bar graph showing maximum peak instantaneous Doppler gradients prior to (Pre) and one day following (Post) balloon pulmonary valvuloplasty, and at intermediate-term (ITFU) and long-term (LTFU) follow-up. Note the significant reduction $(p<0.001)$ after valvuloplasty, which remains unchanged $(p>0.1)$ at ITFU. However, at LTFU there was a further reduction $(p<0.001)$ in the Doppler gradients. The mean + standard deviation (SD) are depicted [20].

in high-80 $\mathrm{s}$ and mid-80 $\mathrm{s}$ at 5 and 10 years following BPV, respectively; but, significant increase in frequency of pulmonary insufficiency (PI) was seen during longterm follow-up evaluation [20].

Restenosis was observed in 8 to $10 \%$ of children at intermediate-term follow-up [19-21]. The predictors of restenosis were balloon/annulus ratio $<1.2$ and imme- diate post-valvuloplasty gradient $\geq 30 \mathrm{mmHg}$ [21]. Repeat BPV for relief of restenosis is feasible and effective [22]. Restenosis that occurs after surgical pulmonary valvotomy can also be relieved by BPV [23]. Infundibular stenosis/gradients develop in nearly $30 \%$ patients with higher incidence in the older patients and in those with more severe obstruction [24]. Infundibular gradien- 


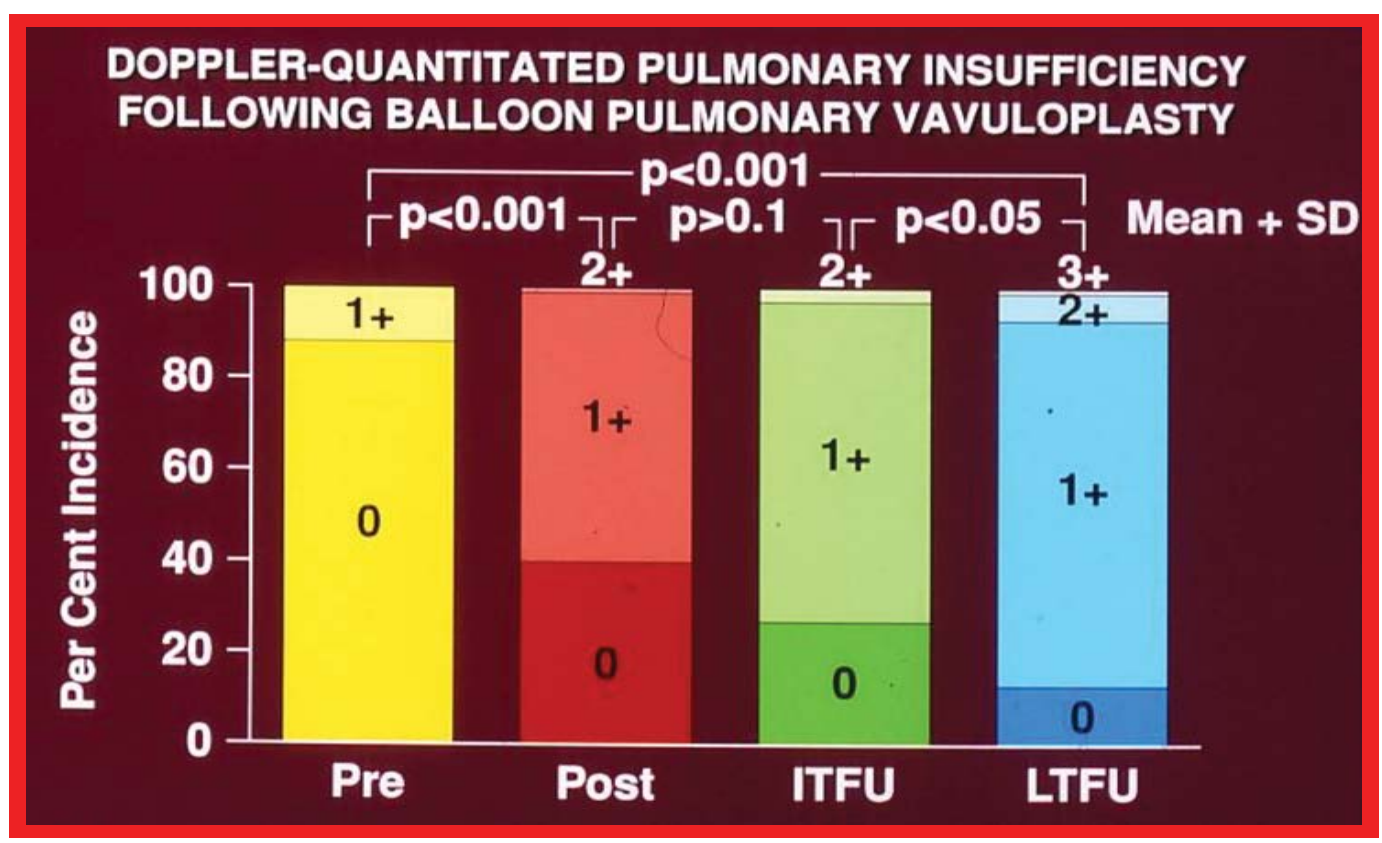

Figure 3: Bar graph demonstrating pulmonary insufficiency (PI) graded by Doppler prior to (Pre) and one day after (Post) balloon pulmonary valvuloplasty and at intermediate-term (ITFU) and long-term (LTFU) follow up. 0, No PI; 1+, 2+, 3+, PI grade. A gradual but significant increase $(p<0.05$ to $p<0.001)$ in the incidence of PI is noted [20].

ts higher than $50 \mathrm{mmHg}$ should receive beta blockade therapy $[24,25]$. The infundibular obstruction regresses at follow-up in the majority of patients with only rare need for surgical intervention $[24,25]$. Right ventricular filling abnormalities do improve following BPV with consequent reduction/reversal of inter-atrial right to left shunt [26]. Relief of pulmonary valve obstruction in patients with dysplastic pulmonary valves is feasible, but may require larger balloons with balloon/annulus ratio of 1.4 to 1.5; the relief of obstruction is dependent upon the presence of commissural fusion [27]. Unsuccessful cases may require surgical excision of the obstructive valve leaflets along with trans-annular patch relief of valve annular obstruction. The role of balloon diameter, balloon length, number of balloons (double vs. single balloon), and pressure, duration and number of balloon inflations on the effectiveness of BPV was also scrutinized $[15,28-30]$. The mechanism by which BPV produces relief of pulmonary valve stenosis appears to be rupture/tear of the fused valve commissures with infrequent valve leaflet tears or avulsion [31].

Electrocardiogram (ECG) is valuable in demonstrating regression of hypertrophy of the right ventricle following BPV, but ECG confirmation for improvement does not become clear until six months following BPV [32]. Echo-Doppler studies are also useful and dependable non-invasive monitoring techniques; the Doppler gradients are usually indicative of residual obstruction and will also identify $\mathrm{PI}[33,34]$. Residual $\mathrm{PI}$ is seen in most of the patients at late follow-up (Figure 3) [20,3537]. Reducing the balloon/annulus ratio to 1.2 to 1.25 at the time of initial BPV was thought to reduce the degree and prevalence of $\mathrm{PI}$ at follow-up [37]; studies to confirm this hypothesis are warranted. There are only a few studies comparing balloon with surgical therapy are available [22]. In the few of these studies, surgical therapy is associated with higher incidence of mortality and morbidity as well as of $\mathrm{PI}$, but with a greater reduction of gradient [22,38]. BPV is also useful in the treatment of the newborn with critical pulmonary stenosis [39-44] and adults with valvar pulmonary stenosis $[38,45]$.

\section{Pulmonary Stenosis Associated with Cyanotic Heart Defects}

Historical aspects, indications, procedure of BPV, and immediate and follow-up results in patients with pulmonary stenosis associated with cyanotic $\mathrm{CHDs}$ were appraised [46-52]. BPV is recommended if the infant/ child needs palliation of pulmonary oligemia but is not a candidate for total surgical correction at presentation. The procedure is indicated if the pulmonary valve obstruction is a significant part of the right ventricular outflow tract stenosis and multiple obstructions in series exist (Figure 4) so that there is likely to be residual subvalvar obstruction following relief of valvar narrowing so that flooding of the lungs is prevented. Increase in systemic arterial saturations immediately after BPV and growth of the pulmonary arteries at follow-up (Figure 5) seem to be the benefits of BPV in this subset of patients.

There are several other cyanotic CHDs that may be benefitted by other types of transcatheter therapeutic methods and these include: 1) Transposition of the great arteries (TGA) with intact ventricular septum: Balloon atrial septostomy and other transcatheter techniques to enlarge the PFO. 2) Severe/critical PS with inter-atrial right-to left shunt: Balloon valvuloplasty. 3) Narrowed systemic-to-pulmonary artery shunts: Balloon angioplasty, stent implantation and 4) Pulmonary atresia with 


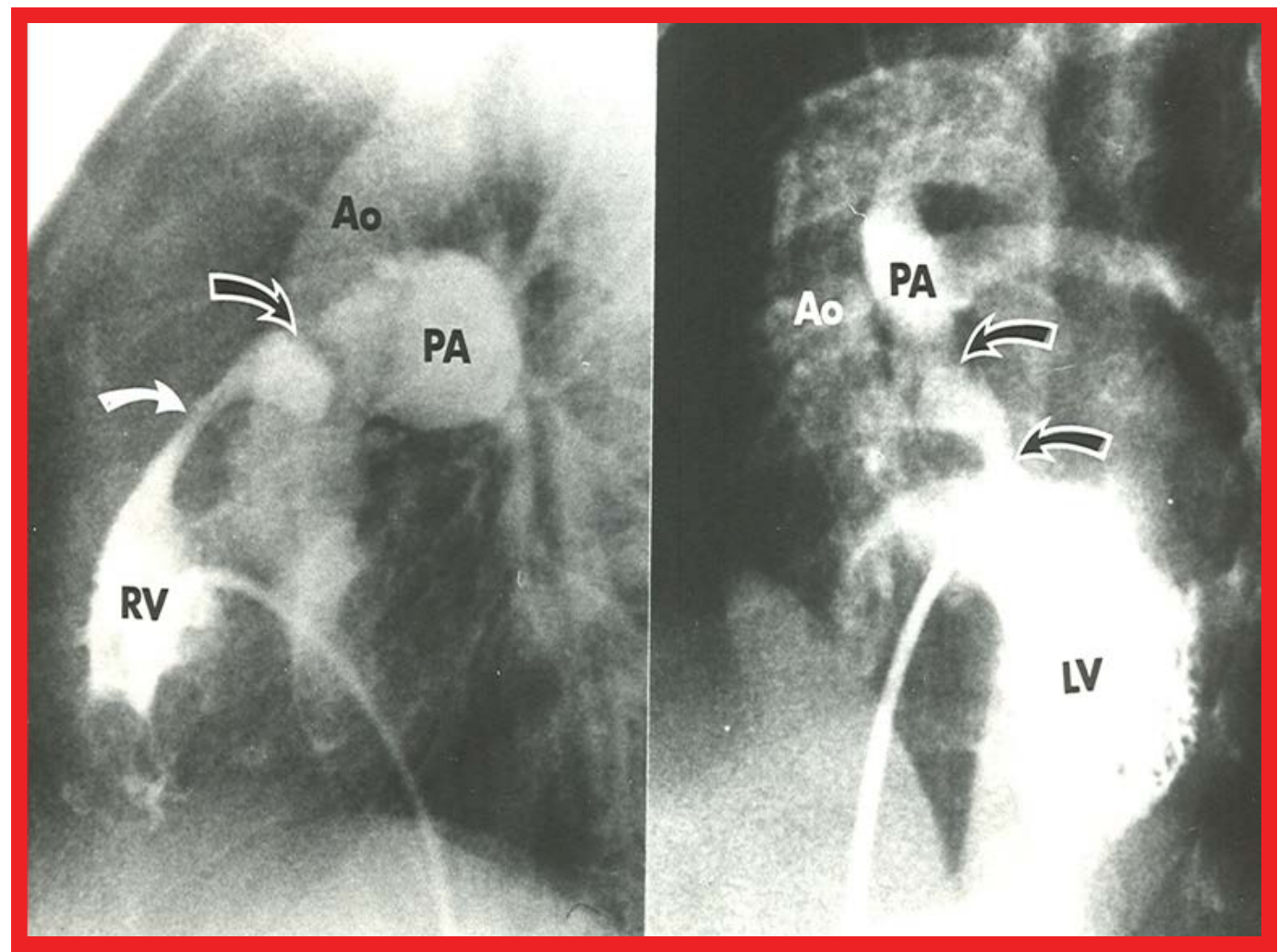

Figure 4: Selected cineangiographic frames from patients with tetralogy of Fallot (left) and d-transposition of the great arteries (right), demonstrating two sites of pulmonary outflow obstruction (two arrows). When the pulmonary valve obstruction is relieved by balloon valvuloplasty, the subvalvar obstruction remains and prevents the flooding of the lungs [48].

Ao: Aorta; LV: Left Ventricle; PA: Pulmonary Artery; RV: Right Ventricle

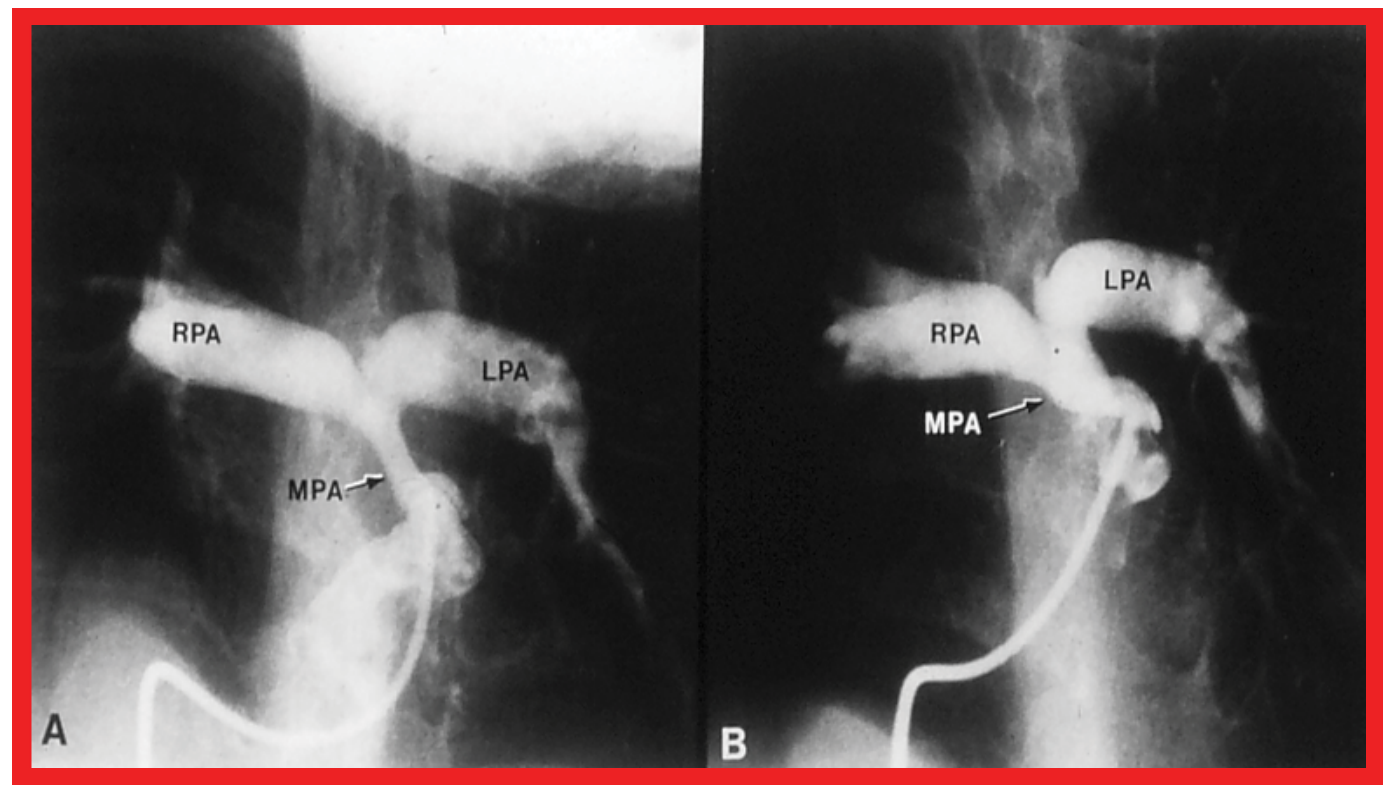

Figure 5: A) Selected frames from pulmonary artery cineangiograms in a sitting-up view in a patient with tetralogy of Fallot, prior to and B) 12 months following balloon pulmonary valvuloplasty. Note the significant improvement in the size of the valve annulus and main pulmonary artery (MPA) at follow-up [48].

LPA: Left Pulmonary Artery; RPA: Right Pulmonary Artery

intact ventricular septum: Radiofrequency perforation and balloon valvuloplasty.

\section{Other Right Ventricular Obstructions}

There are several intra-cavitary right ventricular ob- structions including, isolated infundibular stenosis, double chamber right ventricle, hypertrophic cardiomyopathy involving the right ventricle, and subpulmonary obstructions in morphologic left ventricle in patients with corrected TGA. Most of these can't be addressed 


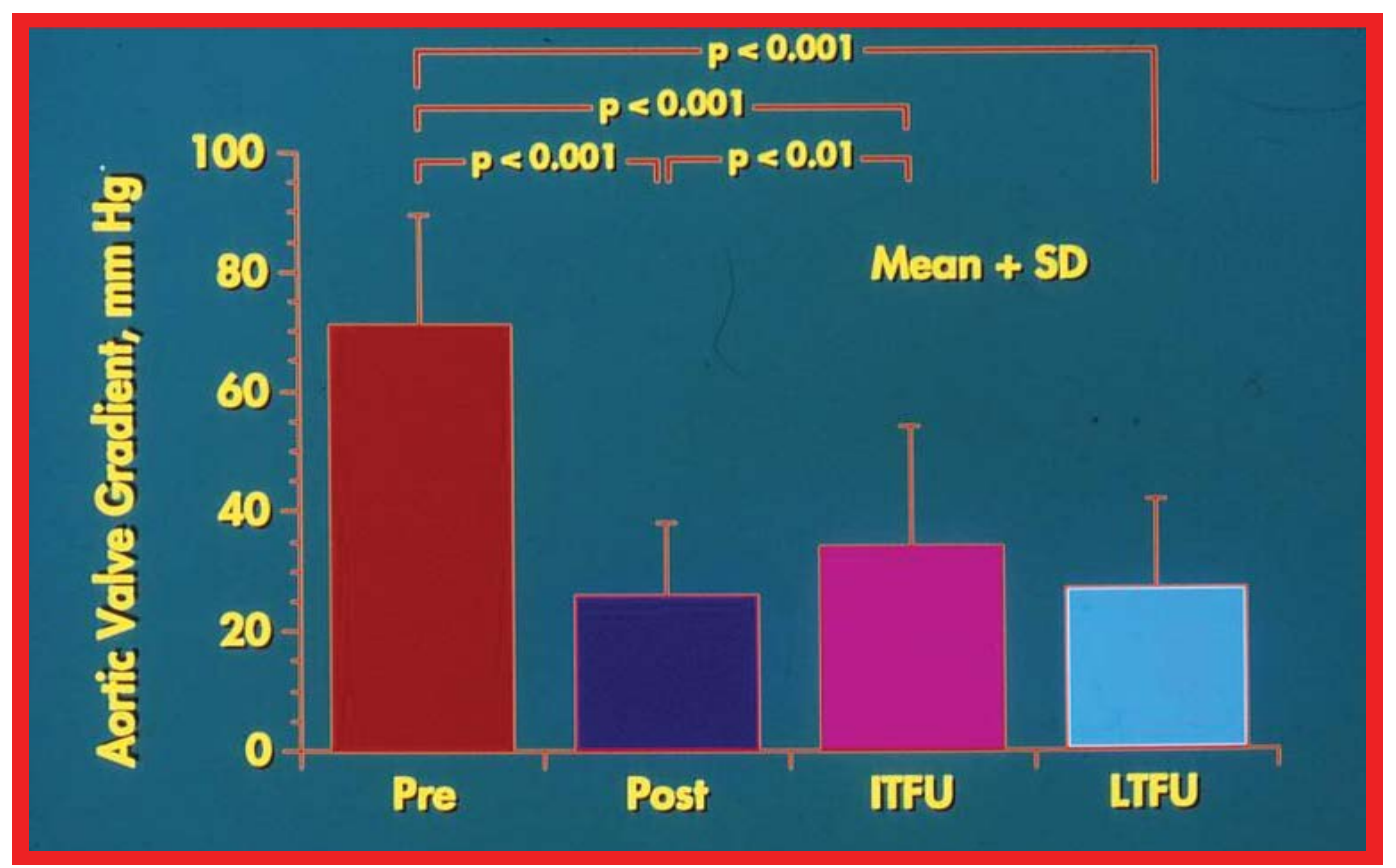

Figure 6: Bar graph showing maximal peak instantaneous Doppler gradients before (Pre) and 1 day after (Post) balloon aortic valvuloplasty, and at intermediate term (ITFU) and late (LTFU) follow-up. There was a significant reduction ( $p<0$ $\sim 001)$ in the gradient after balloon aortic valvuloplasty which remained essentially unchanged $(p>0.1)$ at ITFU (12 \pm 5 months) and at LTFU (3 to 9 years [mean 6 years]). Doppler-derived maximal peak instantaneous gradients at follow-up continued to be lower $(p<0.001)$ than pre-valvuloplasty gradients.

with balloon dilatation $[53,54]$. Supravalvar pulmonary artery stenosis may be produced by multiple causes; discrete obstructive lesions may be adequately relieved by balloon angioplasty while long segment and diffuse obstructive lesions are not amenable to transcatheter balloon therapy [53-55]. Balloon angioplasty of branch pulmonary artery stenosis is successful in only $50 \%$ of the patients even when high pressure balloons are used, and in addition, complications and recurrences are high [53,54]. Therefore, endovascular stents are currently used in the management of branch pulmonary artery stenosis.

\section{Aortic stenosis}

Initially the pathologic and pathophysiologic features of aortic stenosis were reviewed. This is followed by discussion of historical aspects [7-9], indications [56-58], and procedure of balloon aortic valvuloplasty (BAV) [58,59]. Then a presentation of immediate [56], intermediate-term [57-59] and long-term [60] follow-up results (Figure 6) was made which show good results with low residual gradients across the aortic valve and event-free rates of $80 \%, 76 \%, 76 \%$ and $60 \%$ at 1-, 2-, 5- and 10-year follow-up, respectively following BAV. However, considerable increase in prevalence of aortic insufficiency (Al) was seen during long-term follow-up [60,61]. Restenosis occurs in $23 \%$ of children at intermediate-term follow-up [56,62]. The predictors of restenosis were age $\leq 3$ years and immediate post-valvuloplasty gradient $\geq 30 \mathrm{mmHg}[56,62]$. Repeat BAV for restenosis is feasible and effective [22]. Restenosis that follows after surgical valvotomy can also be relieved by
BAV $[57,58]$. Subvalvar gradients develop in a very small percentage of patients and resolve with time [58]. The effect of balloon diameter, balloon length, number of balloons (double vs. single balloon), and pressure, duration and number of balloon inflations during BAV was also scrutinized $[56-58,63]$. The mechanism by which $\mathrm{BAV}$ relieves aortic valve obstruction is by rupture/tear the fused commissures with occasional valve leaflet tear or avulsion $[31,55,57,58]$.

Echo-Doppler studies are helpful and are reliable non-invasive monitoring techniques; the Doppler gradients usually reflect residual obstruction and will also identify Al [56-58,60,61]. Significant residual Al is seen in 24 to $38 \%$ of patients at late follow-up (Figure 7). Quantity of immediate post-valvuloplasty Al appears to predict development of late $\mathrm{Al}$; however, the causes of $\mathrm{Al}$ are not known $[60,61,64]$. There are only a few studies comparing balloon with surgical treatment $[58,59,61]$. Based on these limited data, it appears that BAV is an attractive alternative to surgical valvotomy $[58,59,61]$. BAV is also useful in the management of the neonate with critical aortic valve stenosis $[41-44,58]$ and adults with valvar aortic stenosis $[64,65]$.

We examined the prevalence of abnormalities of arterial pulse and limb growth in patients who have undergone trans-femoral artery balloon dilatations by a comparison of three groups of patients, namely, trans-femoral artery balloon dilatations, retrograde femoral arterial catheterization, and control subjects [66]. Children who had trans-femoral artery balloon dilatation exhibited superficial femoral artery compromise, but did not have significant retardation of limb growth. 


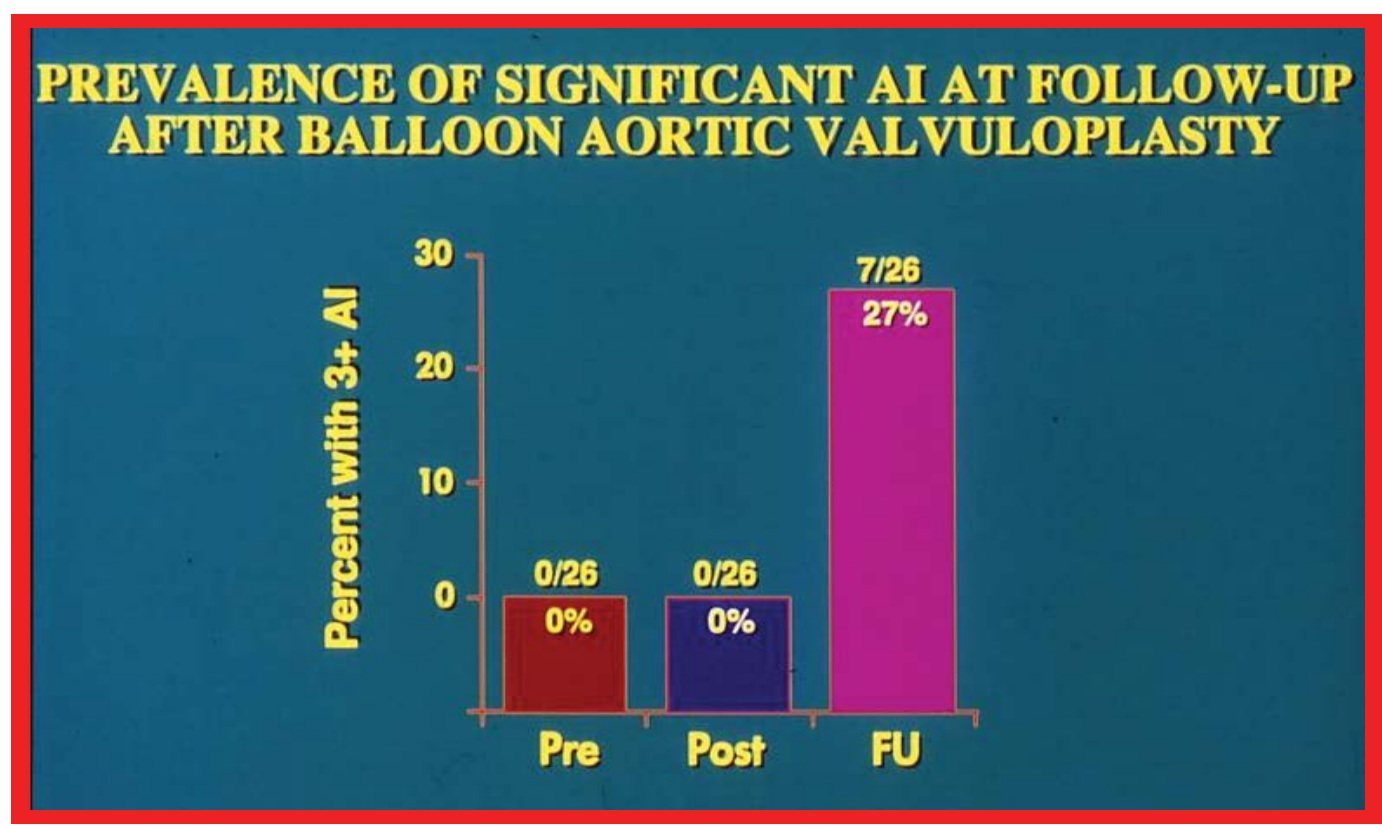

Figure 7: Bar graph demonstrating the prevalence of grade III aortic insufficiency (AI) prior to (Pre), immediately following (Post) balloon aortic valvuloplasty and at late follow-up (FU). Note the significant increase of Al at late follow-up [61].

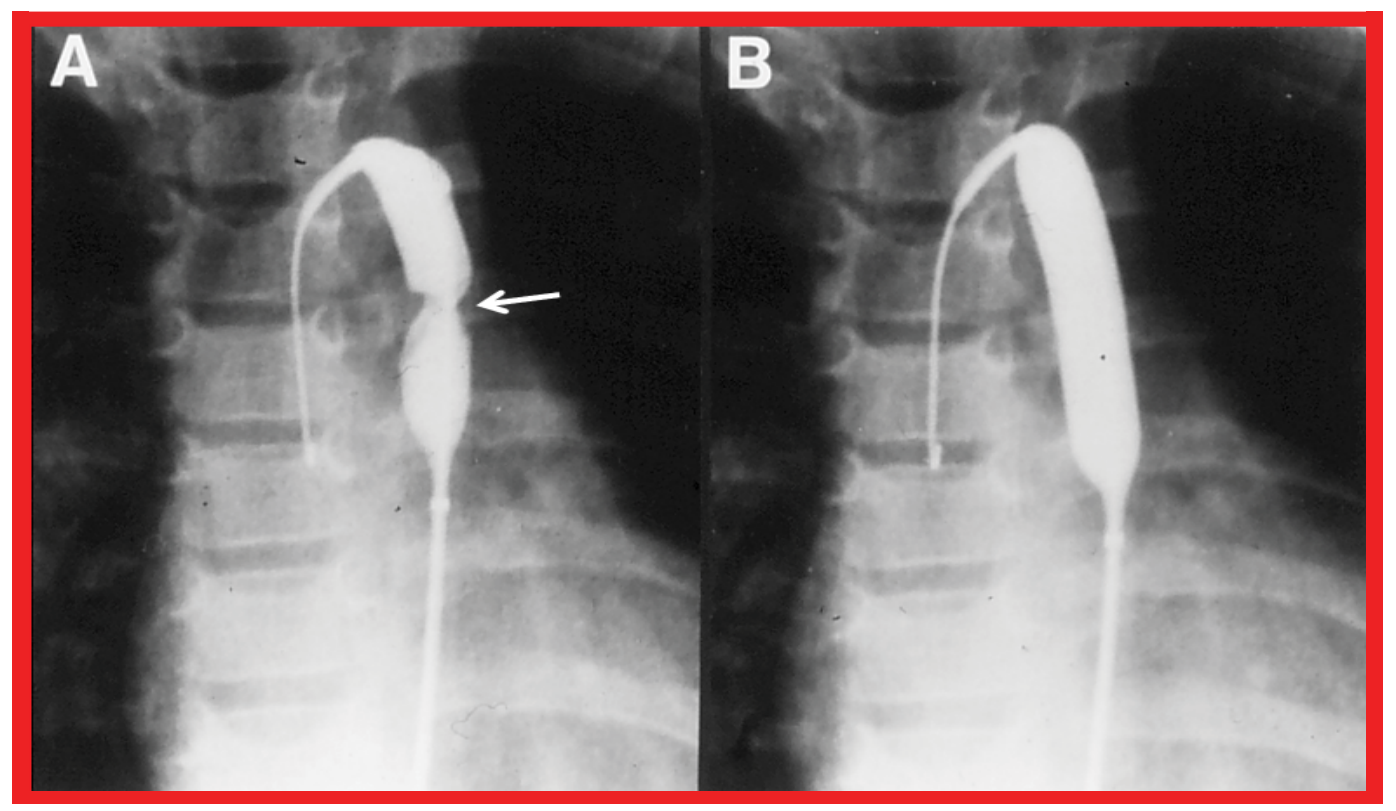

Figure 8: Selected cineflurograpic frames in postero-anterior projection in a child, demonstrating an angioplasty balloon across the aortic coarctation with A) Waisting (arrow) of the balloon during the initial phases of balloon inflation; B) The waist has completely disappeared; with further balloon inflation. The guide wire $(\mathrm{GW})$ is positioned in the ascending aorta (AAo) [73].

This was presumed to be related to development of collateral circulation in children [66].

\section{Fixed subaortic membranous stenosis}

A review of historical aspects [7-9,67], indications [67-69], procedure of balloon dilatation [67,68], and immediate and follow-up results in patients with fixed subaortic membranous stenosis [68] was undertaken. Good results were seen when the membrane was thin, less than $2 \mathrm{~mm}$ [68-70]. The results were poor in patients with thick fibro-muscular ridge and long tubular fibro-muscular tunnel types of subaortic stenosis. Be- cause the immediate and intermediate-term results of balloon dilatation of fixed subaortic membranous stenosis, when it is thin, are encouraging, balloon dilatation may be considered as treatment of choice in the initial management of this type of discrete subaortic membranous stenosis [68-71].

\section{Native coarctation of the aorta}

At first the pathologic features of coarctation of the aorta (CoA) were reviewed. Then, a description of historical aspects [7-9], indications [72-75], and the procedure of balloon angioplasty (Figure 8) ensued [73-75]. 


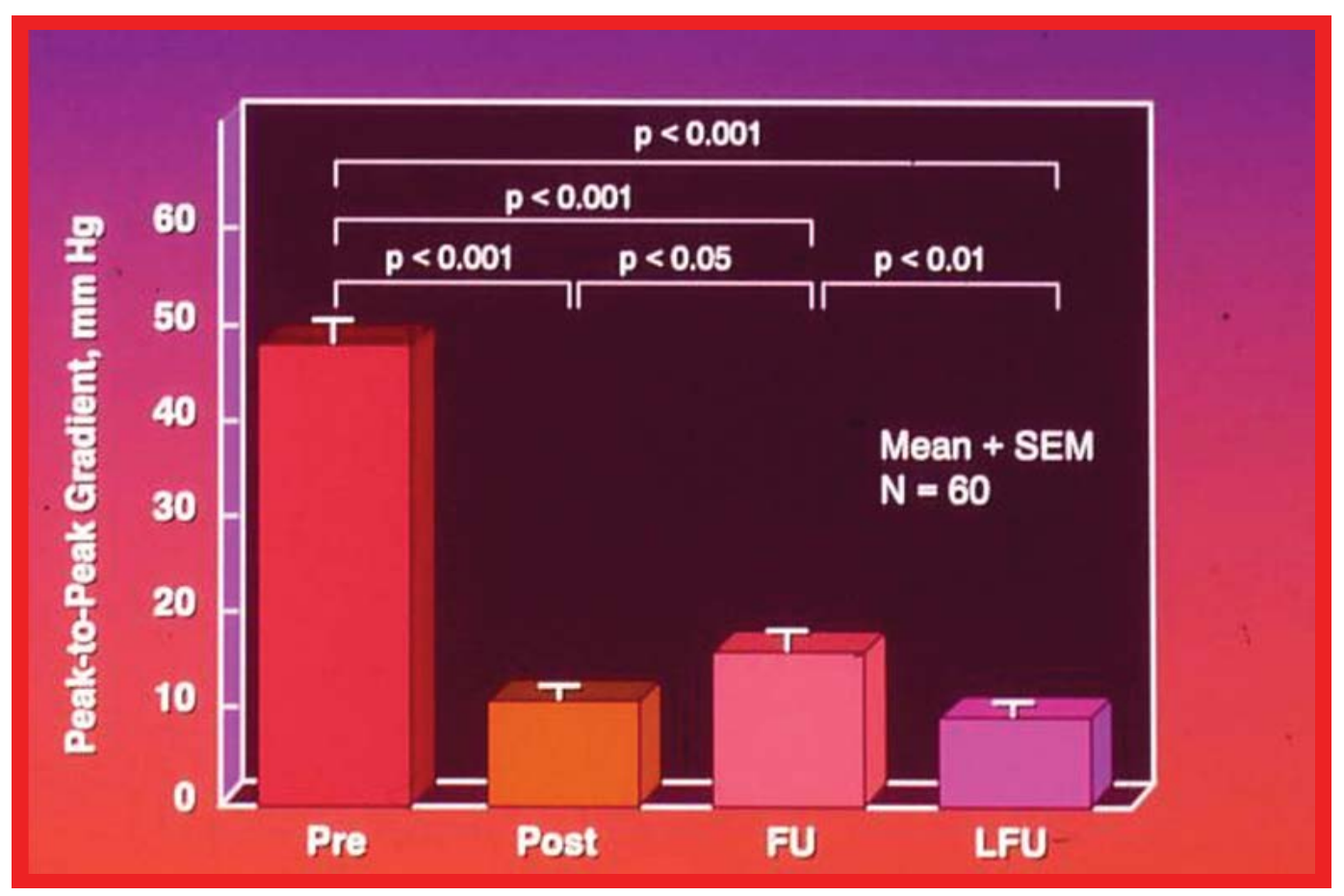

Figure 9: A bar graph of results following balloon angioplasty of native aortic coarctation is shown. The peak-to peak systolic pressure gradients across the coarctation decreased significantly $(p<0.001)$ from their previous values (Pre) to immediately after (Post) balloon angioplasty. However, the gradient increased $(p<0.05)$ slightly at intermediate-term followup (FU). But, these gradients continued to be lower $(p<0001)$ than the pre-angioplasty values. At long-term follow-up (LFU) the arm-leg peak systolic pressure difference, measured by blood pressures, was lower than the coarctation gradients prior to $(p<0.001)$ and at intermediate-term follow-up $(p<0.01)$. The mean + SEM (standard error of mean) are shown. $N$ : number of patients undergoing balloon angioplasty [81].

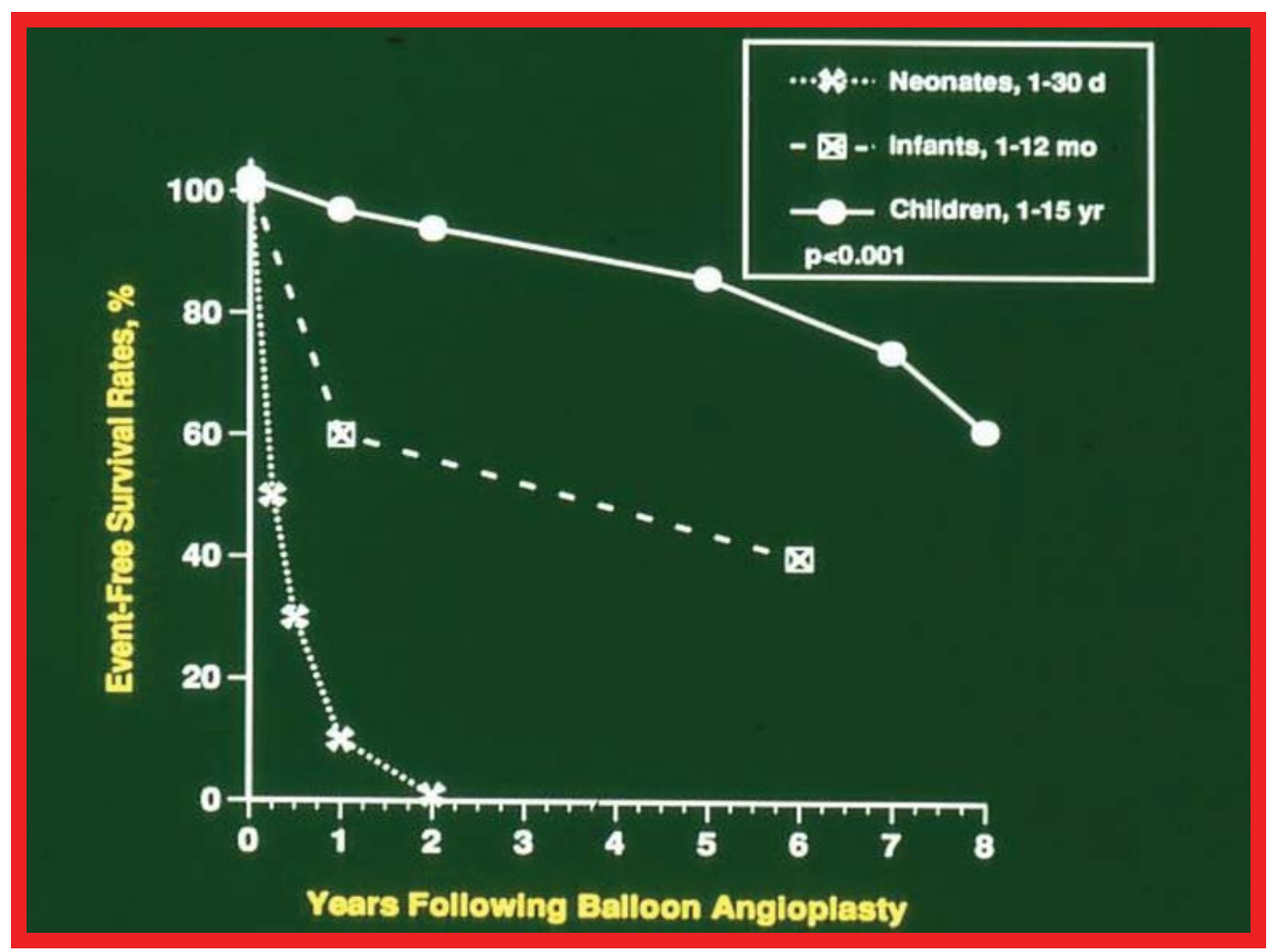

Figure 10: The actuarial event-free survival curves of neonates (<30 days), infants ( 1 to 12 months) and children (1 to 15 years) who had undergone balloon angioplasty of aortic coarctation are drawn. The event-free survival rates are better for the children than for the neonates and infants $(p<0.001)$ [81].

This is followed by a presentation of immediate $[17,76]$, intermediate-term [77-80], and long-term [81] follow-up results (Figure 9). These data indicated that immediate and intermediate-term results are excellent 
for native CoA; however, recoarctation can develop necessitating re-intervention. Aneurysms may occur, but uncommon. During long-term follow-up normal arm blood pressures in most and low blood pressure-determined gradient between arms and legs were demonstrated [81]. Actuarial reintervention rates were shown to be age dependent, the younger the age at initial balloon angioplasty higher the necessity for reintervention (Figure 10) [81]. The balloon angioplasty technique is equally applicable to adult patients with coarctation [82].

Causes of recoarctation were age less than 12 months, aortic isthmus less than $2 / 3$ the size of the ascending aorta immediately proximal to the right innominate artery, coarcted aortic segment less than $3.5 \mathrm{~mm}$ before dilation, and coarcted aortic segment less than $6 \mathrm{~mm}$ after angioplasty; the higher the number of risk factor, the greater the probability of recoarctation [83]. When restenosis occurs, repeat balloon dilatation is feasible and effective in relieving obstruction [22]. Aneurysm may develop following balloon angioplasty, this phenomenon is similar to that seen after surgical procedures. Remodeling of aorta occurs and the aorta assumes a more uniform shape following successful balloon dilatation [84]. Biophysical response of coarcted aortic segment to balloon angioplasty was studied which demonstrated poor recoil in the patients with recoarctation indicating that elastic properties may not have been preserved in the patients with recoarctation [85]. Effect of technical factors on balloon angioplasty results, mechanism of relief of stenosis by balloon angioplasty and utility of echo-Doppler studies in the assessment of results of balloon angioplasty were also reviewed [78]. Comparison of balloon with surgical therapy is problematic. The efficacy of balloon angioplasty appears to be similar to that of surgery and the mortality rates are also similar and are likely to be related to the associated cardiac defects. However, the morbidity and complication rates are higher with surgical intervention than with balloon dilatation $[86,87]$. The controversy with regard to whether balloon angioplasty should be used instead of surgery for native coarctation [88-90] was also reviewed.

The author made several other contributions to the literature which included: trans-ductal balloon angioplasty [91], balloon angioplasty of long segment coarctation [92], and revisiting balloon angioplasty of coarctation in the neonate and young infant to test a hypothesis that balloon angioplasty offers successful palliation, defined as avoiding surgery for 4 weeks along with control of congestive heart failure $[93,94]$ were also discussed.

Although the author initially advocated balloon angioplasty in the neonate, because of high rate of recurrence documented in his and other investigators' experience and common occurrence of varying degrees of hypoplasia of the transverse aortic arch and isthmus in the neonate, surgery is now accepted as preferred alternative in the newborn. Nonetheless, balloon angioplasty of coarctation has a valuable role in critically ill young babies [92,95-97], specially if avoidance of anesthesia or aortic cross-clamping required for surgery is important in the overall management of the baby. In addition, the present trend at the majority of institutions is that the type of intervention to tackle coarctation is mostly dependent upon the age of the patient at presentation and the anatomy of coarctation site (discrete vs. long segment and presence of aneurysms) [98].

Despite acceptable short-term and long-term results of balloon dilatation, some problems remain and include, likelihood of aortic rupture, aneurysm formation, failure to effectively address long-segment, tubular narrowings, and recurrence of stenosis. Apparently secondary to these reasons, stent therapy for aortic coarctation has achieved acceptance over the past decade and a half [99-102]. Then, future directions were briefly reviewed; because the cellular mechanisms for recoarctation are unknown, keeping the coarctation segment open mechanically appears to be an available option. However, the stents do not expand as the child grows; this issue may be addressed by possible uses of biodegradable, growth and "dilatable" types of stents $[93,103]$.

\section{Post-surgical aortic recoarctation}

A review of historical aspects [7-9,104], indications $[86,105,106]$, procedure of balloon angioplasty itself $[86,105-107]$, immediate results $[86,105]$, and intermediate-term $[78,80,105,106]$, and long-term $[75,106]$ follow-up results of post-surgical recoarctation was undertaken. The immediate and follow-up results of balloon angioplasty of postsurgical aortic recoarctation indicate low residual gradients (Figure 11) and normal blood pressures in most of the patients $[75,106]$. Nonetheless, the requirement for transcatheter or surgical re-intervention to manage recoarctations, aortic arch/isthmic narrowing and aneurysms in some patients is present. In older subjects, stents may are useful in the treatment of these patients. One of the causes of recoarctation was hypoplasia of the aortic segment proximal to recoarctation site; this is not too dissimilar to the causes of recoarctation following balloon angioplasty of native CoA. Remodeling of the aorta also occurs in post-surgical balloon angioplasty children in a manner similar to that seen with native CoA. A review of usefulness of echo-Doppler studies $[86,105,106]$ in the assessment of results of balloon angioplasty of post-surgical recoarctations and a comparison with surgical therapy was also undertaken [86].

\section{Miscellaneous obstructive lesions}

Percutaneous treatment of miscellaneous congenital and acquired obstructive lesions was scrutinized. These are: Narrowed Blalock-Taussig shunts $[48,49,108]$, 


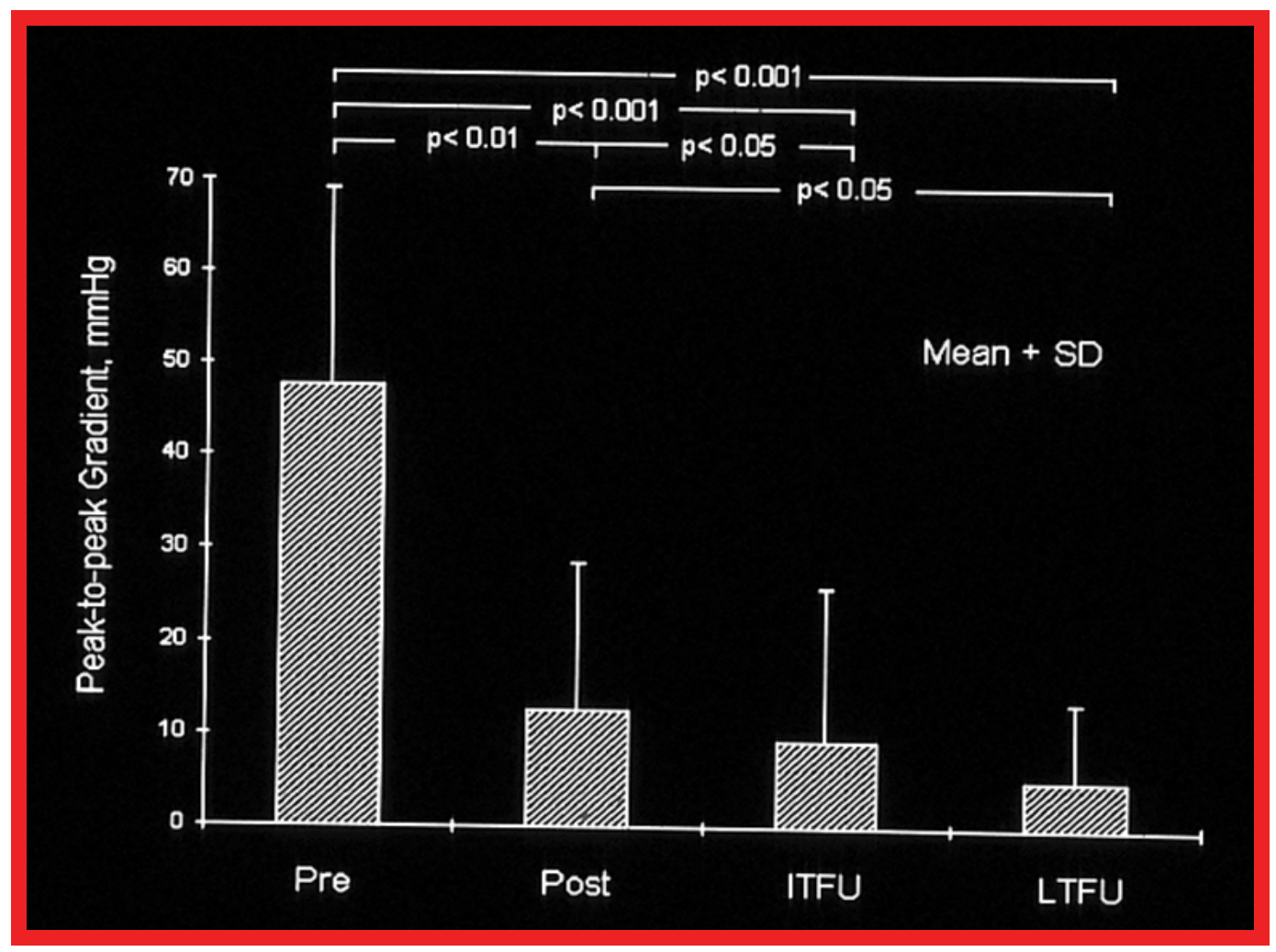

Figure 11: A bar graph of the immediate and follow-up results after balloon angioplasty of postsurgical aortic recoarctation is shown. The peak-to-peak systolic pressure gradients $(\mathrm{mmHg})$ across the coarctation decreased significantly $(p<0.001)$ from before (Pre) to immediately after (Post) balloon angioplasty. They decreased further $(p<0.05)$ at intermediate-term (ITFU) and at long- term follow-up (LTFU). The ITFU and LTFU gradients remained remarkably lower $(p<0.001)$ than those prior to balloon angioplasty. The mean and standard deviation (SD) are shown [106].

tricuspid and mitral valve stenoses [109], stenotic bioprosthetic valves (both homografts and heterografts) [110], baffle obstruction following Senning/Mustard operation [111], stenosis of superior and inferior vena cavae [109], obstructed total anomalous pulmonary venous connection [109], obstructed anostomotic site following total anomalous pulmonary venous connection repair [109], PFO [109], PDA [109] and coronary artery stenosis in Takayasu's arteritis [112]. A review of the indications for interventions, the technique of balloon dilatation, and immediate and follow-up results for each of the above, where available, was performed. Balloon therapy indications for are generally similar to those utilized for surgery. The technique involves positioning an appropriate-sized balloon catheter across the stenotic lesion and inflating the balloon two or three times. The balloon size selected is comparable to the valve annulus diameter in the valvar obstructive lesions and two or more times the diameter of the vascular stenoses. In the latter condition, the size of the balloon should not generally exceed 1.5 times the size of the adjacent normal blood vessel. The immediate results following balloon dilatation were excellent in some of the disease entities reviewed above and were marginal in other lesions. There is a dearth of data on the long-term follow-up results. Complications are generally negligible. However, there is no information comparing surgical with balloon therapy. The majority of interventional car- diologists advocated these procedures because there is no requirement for general anesthesia, thoracotomy, cardiopulmonary bypass, and prolonged hospitalization associated with the surgical therapy. Other advantages mentioned are lack of residual scar of the surgery, reduced psychological trauma, and less expense. For vascular obstructive lesions not amenable to balloon angioplasty, employing stents has become a management option [99-102].

\section{References}

1. Rao PS (2020) Pediatric cardiology: How it has evolved over the last 50 years. Cambridge Scholars Publishing, New Castle upon Tyne, United Kingdom.

2. Rubio-Alvarez V, Limon-Lason R, Soni J (1953) Valvalotomias intracardiacas por medico de un cateter. Arch Inst Cardiol Mex 23: 183-192.

3. Rubio V, Limon-Lason R (1954) Treatment of pulmonary stenosis and of tricuspid valve stenosis using a modified catheter. Second World Congress on Cardiology, 11: 205.

4. Dotter CT, Judkins MP (1964) Transluminal treatment of arteriosclerotic obstruction. Description of a new technique and a preliminary report of its application. Circulation 30: 654-670.

5. Rashkind WJ, Miller WW (1966) Creation of an atrial septal defect without thoracotomy. A palliative approach to complete transposition of the great arteries. JAMA 196: 991992.

6. Porstmann W, Wierny L, Warnke H (1967) Der Verschluss 
des Ductus arteriosus persistens ohne thorakotomie (1, Miffeilung). Thoraxchivargie 15: 109-203.

7. Rao PS (1993) Historical aspects of therapeutic catheterization. In: Rao PS, Transcatheter therapy in pediatric cardiology. Wiley-Liss, New York, 1-6.

8. Rao PS (2012) Historical aspects of transcatheter treatment of heart disease in children. Pediat Therapeut S5: 002.

9. Rao PS (2015) History of Transcatheter Interventions in Pediatric Cardiology. In: Vijayalakshmi IB, Cardiac catheterization and imaging (From Pediatrics to Geriatrics). Jaypee Publications, New Delhi, India, 3-20.

10. Rao PS (1988) Indications for balloon pulmonary valvuloplasty. Am Heart J 116: 1661-1662.

11. Rao PS (2007) Percutaneous balloon pulmonary valvuloplasty: State of the art. Catheter Cardiovasc Interv 69: 747763.

12. Rao PS (2007) Pulmonary valve stenosis. In: Sievert $H$, Qureshi SA, Wilson N, Hijazi ZM, Percutaneous interventions for congenital heart disease. Informa Health Care, Oxford, UK, 185-195.

13. Rao PS (2014) Pulmonary valve disease: Pulmonary valve stenosis. In: Sievert H, Qureshi SA, Wilson N, Hijazi Z, Interventions in structural, valvular and congenital heart disease. Chapter 31, CRC Press, 297-308.

14. Radtke W, Keane JF, Fellows KE, Lang P, Lock JE (1986) Percutaneous balloon valvotomy of congenital pulmonary stenosis using oversized balloons. J Am Coll Cardiol 8: 909-915.

15. Rao PS (1987) Influence of balloon size on short-term and long-term results of balloon pulmonary valvuloplasty. Tex Heart Inst J 14: 57-61.

16. Rao PS, Mardini MK (1985) Pulmonary valvotomy without thoracotomy: The experience with percutaneous balloon pulmonary valvuloplasty. Ann Saudi Med 5: 149-155.

17. Rao PS (1986) Transcatheter treatment of pulmonary stenosis and coarctation of the aorta: Experience with percutaneous balloon dilatation. Br Heart J 56: 250-258.

18. Rao PS, Fawzy ME, Solymar L, Mardini MK (1988) Longterm results of balloon pulmonary valvuloplasty of valvar pulmonic stenosis. Am Heart J 115: 1291-1296.

19. Rao PS (1989) Balloon pulmonary valvuloplasty: A review. Clin Cardiol 12: 55-74

20. Rao PS, Galal O, Patnana M, Buck S, Wilson A (1998) Three-to-ten-year follow-up results of balloon pulmonary valvuloplasty. Heart 80: 591-595.

21. Rao PS, Thapar MK, Kutayli F (1988) Causes of restenosis after balloon valvuloplasty for valvuar pulmonary stenosis. Am J Cardiol 62: 979-982.

22. Rao PS, Galal O, Wilson AD (1996) Feasibility and effectiveness of repeated balloon dilatation of restenosed congenital obstructions after previous balloon valvuloplasty/ angioplasty. Am Heart J 132: 403-407.

23. Rao PS (1993) Balloon pulmonary valvuloplasty for isolated pulmonic stenosis. In: Rao PS, Transcatheter therapy in pediatric cardiology. Chapter 6, Wiley-Liss, Inc., New York, 59-104.

24. Thapar MK, Rao PS (1989) Significance of infundibular obstruction following balloon valvuloplasty for valvar pulmonic stenosis. Am Heart J 118: 99-103.

25. Fontes VF, Esteves CA, Sousa JE, Silva MV, Bembom MC
(1988) Regression of infundibular hypertrophy after pulmonary valvotomy for pulmonic stenosis. Am J Cardiol 62: 977-979.

26. Rao PS (1992) Right ventricular filling following balloon pulmonary valvuloplasty. Am Heart J 123: 1084-1086.

27. Rao PS (1988) Balloon dilatation in infants and children with dysplastic pulmonary valves: Short-term and intermediate-term results. Am Heart J 116: 1168-1173.

28. Rao PS (1988) How big a balloon and how many balloons for pulmonary valvuloplasty? Am Heart J 116: 577-580.

29. Rao PS (1988) Further observations on the effect of balloon size on the short-term and intermediate-term results of balloon dilatation of the pulmonary valve. $\mathrm{Br}$ Heart $\mathrm{J} 60$ : 507-511.

30. Rao PS, Fawzy ME (1988) Double balloon technique for percutaneous balloon pulmonary valvuloplasty: Comparison with single balloon technique. J Interventional Cardiol 1: $257-262$

31. Thapar MK, Rao PS (1993) Mechanism of valvuloplasty/ angioplasty. In: Rao PS, Transcatheter therapy in pediatric cardiology. Wiley-Liss, New York, 45-58.

32. Rao PS, Solymar L (1988) Electrocardiographic changes following balloon dilatation of valvar pulmonic stenosis. J Interventional Cardiol 1: 189-197.

33. Rao PS (1986) Value of echo-Doppler studies in the evaluation of the results of balloon pulmonary valvuloplasty. $J$ Cardiovasc Ultrasonography 5: 309-314.

34. Rao PS (1987) Doppler ultrasound in the prediction of transvalvar pressure gradients in patients with valvar pulmonary stenosis. Int J Cardiol 15: 195-203.

35. Rao PS (1999) Long-term follow-up results after balloon dilatation of pulmonic stenosis, aortic stenosis and coarctation of the aorta: A review. Progr Cardiovasc Dis 42: 59-74.

36. Berman Jr W, Fripp RR, Raisher BD, Yabek SM (1999) Significant pulmonary valve incompetence following oversize balloon pulmonary valvuloplasty in small infants: A longterm follow-up study. Catheter Cardiovasc Interv 48: 61-65.

37. Rao PS (2000) Late pulmonary insufficiency after balloon dilatation of the pulmonary valve. Catheter Cardiovasc Interv 49: 118-119.

38. Rao PS (2015) Balloon valvuloplasty for pulmonary stenosis. In: Vijayalakshmi IB, Cardiac catheterization and imaging (From Pediatrics to Geriatrics). Jaypee Publications, New Delhi, India,149-174.

39. Rao PS (1996) Balloon valvuloplasty in the neonate with critical pulmonary stenosis. J Am Coll Cardiol 27: 479-480.

40. Jureidini SB, Rao PS (1996) Critical pulmonary stenosis in the neonate: Role of transcatheter management. J Invasive Cardiol 8: 326-331.

41. Rao PS (2007) Role of interventional cardiology in neonates: Part II - Balloon angioplasty/valvuloplasty. Neonatology Today 2: 1-12.

42. Rao PS (2008) Role of interventional cardiology in neonates: Part II - Balloon angioplasty/valvuloplasty. Congenital Cardiol Today 6: 1-14.

43. Rao PS (2015) Catheter interventions in the neonate: Part II - Balloon angioplasty/valvuloplasty. In: Rao PS, Vidyasagar D, Perinatal Cardiology: A multidisciplinary approach. Minneapolis, MN, Cardiotext Publishing.

44. Rao PS (2015) Neonatal catheter interventions. In: Vija- 
yalakshmi IB, Cardiac catheterization and imaging (From Pediatrics to Geriatrics), Jaypee Publications, New Delhi, India, 388-432.

45. Bahl VK, Chandra S, Goel A, Goswami KC, Wasir HS (1997) Versatility of Inoue balloon catheter. Int J Cardiol 59: 75-83.

46. Rao PS (1987) Balloon pulmonary valvuloplasty for complex cyanotic heart defects. Presented at the Pediatric Cardiology International Congress, Vienna, Austria, 21-25.

47. Rao PS, Brais M (1988) Balloon pulmonary valvuloplasty for congenital cyanotic heart defects. Am Heart J 115: $1105-1110$.

48. Rao PS, Wilson AD, Thapar MK, Brais M (1992) Balloon pulmonary valvuloplasty in the management of cyanotic congenital heart defects. Cathet Cardiovasc Diagn 25: 1624.

49. Rao PS (1992) Transcatheter management of cyanotic congenital heart defects: A review. Clin Cardiol 15: 483-496.

50. Rao PS (1993) Role of balloon dilatation and other transcatheter methods in the treatment of cyanotic congenital heart defects. In: Rao PS, Transcatheter therapy in pediatric cardiology. Wiley-Liss, New York, 229-253.

51. Rao PS (2007) Pulmonary valve in cyanotic heart defects with pulmonary oligemia. In: Sievert H, Qureshi SA, Wilson $\mathrm{N}$, Hijazi Z, Percutaneous interventions in congenital heart disease. Informa Health Care, Oxford, UK, 197-200.

52. Rao PS (2014) Pulmonary valve disease: Pulmonary valve in cyanotic heart defects with pulmonary oligemia. In: Sievert H, Qureshi SA, Wilson N, Hijazi Z, Interventions in structural, valvular and congenital heart disease. Chapter 33, CRC Press, 297-308.

53. Rao PS, Thapar MK (1993) Balloon dilatation of other congenital and acquired stenotic lesions of the cardiovascular system. In: Rao PS, Transcatheter therapy in pediatric cardiology. Chapter 15, Wiley-Liss, Inc., New York, 275-319.

54. Rao PS (2000) Pulmonary valve disease. In: Alpert JS, Dalen JE, Rahimtoola S, Valvular heart disease. ( $3^{\text {rd }}$ edn), Lippincott Raven, Philadelphia, 339-376.

55. Rao PS (1989) Balloon angioplasty and valvuloplasty in infants, children and adolescents. Curr Probl Cardiol 14: 417-497.

56. Rao PS, Thapar MK, Wilson AD, Levy JM, Chopra PS (1989) Intermediate-term follow-up results of balloon aortic valvuloplasty in infants and children with special reference to causes of restenosis. Am J Cardiol 64: 1356-1360.

57. Rao PS (1990) Balloon aortic valvuloplasty in children. Clin Cardiol 13: 458-466.

58. Rao PS (1993) Balloon valvuloplasty for aortic stenosis. In: Rao PS, Transcatheter therapy in pediatric cardiology. Chapter 7, Wiley-Liss, Inc., New York, 105-127.

59. Agu NC, Rao PS (2012) Balloon aortic valvuloplasty. Pediat Therapeut S5: 004

60. Galal O, Rao PS, Al-Fadley F, Wilson AD (1997) Follow-up results of balloon aortic valvuloplasty in children with special reference to causes of late aortic insufficiency. Am Heart J 133: 418-427.

61. Rao PS (1998) Balloon aortic valvuloplasty. J Intervent Cardiol 11: 319-329.

62. Rao PS (1990) Causes of restenosis following balloon angioplasty/valvuloplasty: A review. Pediatr Rev Commun 4: 157-172.
63. Rao PS (1989) Double balloon aortic valvuloplasty in children. J Am Coll Cardiol 13: 1216-1218.

64. Rao PS (2016) Balloon aortic valvuloplasty. Indian Heart J 68: $592-595$

65. Awasthy N, Garg R, Radhakrishnan S, Shrivastava S (2016) Long term results of percutaneous balloon valvuloplasty of congenital aortic stenosis in adolescents and young adults. Indian Heart J 68: 604-611.

66. Lee HY, Reddy SC, Rao PS (1997) Evaluation of superficial femoral artery compromise and limb growth retardation after transfemoral artery balloon dilatations. Circulation 95: 974-980.

67. Suárez de Lezo J, Pan M, Sancho M, Herrera N, Arizon J, et al. (1986) Percutaneous transluminal balloon dilatation for discrete subaortic stenosis. Am J Cardiol 58: 619-621.

68. Rao PS, Wilson AD, Chopra PS (1990) Balloon dilatation for discrete subaortic stenosis: Immediate and intermediate-term results. J Invasive Cardiol 2: 65-71.

69. Rao PS (1993) Balloon dilatation of fixed subaortic stenosis. In: Rao PS, Transcatheter therapy in pediatric cardiology. Chapter 9, Wiley-Liss, Inc., New York, 149-153.

70. Shrivastava S, Dev V, Bahl VK, Saxena A (1991) Echocardiographic determinants of outcome after percutaneous transluminal balloon dilatation of discrete subaortic stenosis. Am Heart J 122: 1323-1326.

71. Rao PS (1999) Balloon angioplasty of fixed subaortic stenosis. J Invasive Cardiol 11: 197-199.

72. Rao PS (1993) Balloon angioplasty of native aortic coarctation. In: Rao PS, Transcatheter therapy in pediatric cardiology. Wiley-Liss, New York, 153-196.

73. Rao PS (1989) Which aortic coarctations should we balloon-dilate? Am Heart J 117: 987-989.

74. Rao PS (1995) Coarctation of the aorta. In: Ram CVS, Kurtzman NA, Secondary forms of hypertension. Volume 15, Seminars in Nephrology, WB Saunders, Philadelphia, 81-105.

75. Rao PS (2015) Percutaneous management of aortic coarctation. In: Vijayalakshmi IB, Cardiac catheterization and imaging (From Pediatrics to Geriatrics). Jaypee Publications, New Delhi, India, 433-471.

76. Rao PS, Mardini MK, Najjar H (1986) Relief of coarctation of the aorta without thoracotomy: The experience with percutaneous balloon angioplasty. Ann Saudi Med 6: 193-203.

77. Rao PS, Najjar HN, Mardini MK, Solymar L, Thapar MK (1988) Balloon angioplasty for coarctation of the aorta: Immediate and long-term results. Am Heart J 115: 657-665.

78. Rao PS (1989) Balloon angioplasty of aortic coarctation: A review. Clin Cardiol 12: 618-628.

79. Rao PS, Thapar MK, Galal O, Wilson AD (1990) Follow-up results of balloon angioplasty of native coarctation in neonates and infants. Am Heart J 120: 1310-1314.

80. Rao PS, Chopra PS (1991) Role of balloon angioplasty in the treatment of aortic coarctation. Ann Thorac Surg 52: 621-631.

81. Rao PS, Galal O, Smith PA, Wilson AD (1996) Five-to-nine-year follow-up results of balloon angioplasty of native aortic coarctation in infants and children. J Am Coll Cardiol 27: $462-470$.

82. Attia IM, Lababidi ZA (1988) Early results of balloon angioplasty of native aortic coarctations in young adults. Am J Cardiol 61: 930-931. 
83. Rao PS, Thapar MK, Kutayli F, Carey P (1989) Causes of recoarctation after balloon angioplasty of unoperated aortic coarctations. J Am Coll Cardiol 13: 109-115.

84. Rao PS, Carey P (1989) Remodeling of the aorta after successful balloon coarctation angioplasty. J Am Coll Cardiol 14: $1312-1317$.

85. Rao PS, Waterman B (1998) Relation of biophysical response of coarcted aortic segment to balloon dilatation with development of recoarctation following balloon angioplasty of native coarctation. Heart 79: 407-411.

86. Rao PS (1993) Balloon angioplasty of aortic recoarctation following previous surgery. In: Rao PS, Transcatheter therapy in pediatric cardiology. Wiley-Liss, New York, 197-212.

87. Rao PS, Chopra PS, Koscik R, Smith PA, Wilson AD (1994) Surgical versus balloon therapy for aortic coarctation in infants $\leq 3$ months old. J Am Coll Cardiol 23: 1479-1483.

88. Rao PS (1990) Balloon angioplasty of native coarctations. Am J Cardiol 66: 1401.

89. Rao PS (1995) Should balloon angioplasty be used instead of surgery for native aortic coarctation? Br Heart $\mathrm{J} 74$ : 578-579.

90. Rao PS (1996) Should balloon angioplasty be used as a treatment of choice for native aortic coarctations? J Invasive Cardiol 8: 301-313.

91. Rao PS, Solymar L (1988) Transductal balloon angioplasty for coarctation of the aorta in the neonate: Preliminary observations. Am Heart J 116: 1558-1562.

92. Rao PS, Singh GK, Balfour IC, Jureidini SB, Fiore AC (1999) Balloon angioplasty of long-segment aortic coarctation in the neonate. J Invasive Cardiol 11: 734-738.

93. Rao PS (2001) Current status of balloon angioplasty for neonatal and infant aortic coarctation. Progress Pediat Cardiol 14: 35-44.

94. Rao PS, Jureidini SB, Balfour IC, Singh GK, Chen S-C (2003) Severe aortic coarctation in infants less than 3 months: Successful palliation by balloon angioplasty. J Invasive Cardiol 15: 202-208.

95. Rao PS, Wilson AD, Brazy J (1992) Transumbilical balloon coarctation angioplasty in neonates with critical aortic coarctation. Am Heart J 124: 1622-1624.

96. Saluhuddin N, Wilson AD, Rao PS (1991) An unusual presentation of coarctation of the aorta in infancy: Role of balloon angioplasty in the critically ill infant. Am Heart J 122 $1772-1775$.

97. Rao PS (2005) Balloon angioplasty for native aortic coarctation in neonates and infants. Cardiology Today 9: 94-99.

98. Doshi AR, Rao PS (2012) Coarctation of aorta-management options and decision making. Pediat Therapeut S5: 006 .
99. Rao PS (2001) Stents in the management of congenital heart disease in pediatric and adult patients. Indian Heart $\mathrm{J}$ 53: $714-730$

100. Rao PS (2003) Newer stents in the management of vascular stenoses in children. In: Rao PS, Kern MJ, Catheter based devices for treatment of noncoronary cardiovascular disease in adults and children. Chapter 39, Lippincott, Williams \& Wilkins, Philadelphia, PA.

101. Sahu R, Rao PS (2012) Transcatheter stent therapy in children: An update. Pediat Therapeut S5: 001.

102. Rao PS (2015) Stents in the management of vascular obstructive lesions associated with congenital heart disease. In: Vijayalakshmi IB, Cardiac catheterization and imaging (From Pediatrics to Geriatrics). Jaypee Publications, New Delhi, India, 573-598.

103. Rao PS (2014) Future directions in the management of aortic coarctation in young patients. Pediat Therapeut 4: e125.

104. Singer MI, Rowen M, Dorsey TJ (1982) Transluminal aortic balloon angioplasty for coarctation of the aorta in the newborn. Am Heart J 103: 131-132.

105. Rao PS, Wilson AD, Chopra PS (1990) Immediate and follow-up results of balloon angioplasty of postoperative recoarctation in infants and children. Am Heart J 120: 1315-1320.

106. Siblini G, Rao PS, Nouri S, Ferdman B, Jureidini SB, et al. (1998) Long-term follow-up results of balloon angioplasty of postoperative aortic recoarctation. Am J Cardiol 81: 61-67.

107. Rao PS (1993) Balloon angioplasty of aortic recoarctation. Am J Cardiol 71: 256-257.

108. Rao PS, Levy JM, Chopra PS (1990) Balloon angioplasty of stenosed Blalock-Taussig anastomosis: Role of balloon-on-a-wire in dilating occluded shunts. Am Heart J 120: 1173-1178.

109. Rao PS (1993) Transcatheter therapy in pediatric cardiology. Chapters 8, 15 and 22b, Wiley-Liss, Inc., New York.

110. Rao PS (1993) Balloon dilatation of stenotic bioprosthetic valves. In: Rao PS, Transcatheter therapy in pediatric cardiology. Chapter 14, Wiley-Liss, Inc., New York, 255-274.

111. Rao PS, Wilson AD (1992) Chylothorax, an unusual complication of baffle obstruction following Mustard operation: Successful treatment with balloon angioplasty. Am Heart J 123: 244-248.

112. Lee HY, Rao PS (1996) Percutaneous transluminal coronary angioplasty in Takayasu's arteritis. Am Heart J 132: 1084-1086 